\title{
Suppressive Effects of Anti-inflammatory Agents on Human Endothelial Cell Activation and Induction of Heat Shock Proteins
}

\author{
Albert Amberger, ${ }^{1}$ Monika Hala, ${ }^{1}$ Maria Saurwein-Teissl, \\ Bernhard Metzler, ${ }^{1}$ Beatrix Grubeck-Loebenstein, ${ }^{1}$ Qingbo $\mathrm{Xu}^{1}$ \\ and Georg Wick ${ }^{1,2}$ \\ ${ }^{1}$ Institute for Biomedical Aging Research, Austrian Academy of \\ Sciences, Innsbruck, Austria \\ ${ }^{2}$ Institute for General and Experimental Pathology, Medical School, \\ University of Innsbruck, Innsbruck, Austria
}

Accepted December 23, 1998.

\begin{abstract}
Background: Studies from our laboratory have shown that the earliest stages of atherosclerosis may be mediated by an autoimmune reaction against heat shock protein 60 (Hsp60). The interactions of Hsp60-specific T cells with arterial endothelial cells (EC) require expression of both Hsp60 and certain adhesion molecules shown to be induced simultaneously in EC by mechanical and other types of stress. Recently, it was shown that suppression of $\mathrm{T}$ cell-mediated immune responses by cyclosporin A (CyA) enhanced atherosclerotic lesion formation in mice. In contrast, aspirin was found to lower the risk of myocardial infarction in men. These conflicting observations may be due to different effects of anti-inflammatory agents on adhesion molecule and Hsp expression in EC, respectively.

Material and Methods: In the present study, we analyzed the effects of CyA, aspirin, and indomethacin on T cell proliferation using a proliferation assay. To explore the expression of adhesion molecules, monocyte chemoattractant protein-1 (MCP-1), and Hsp60 in human umbilical vein endothelial cells (HUVECs), Northern blot analyses were used. To examine the activation status of the transcription factors nuclear factor $\kappa \mathrm{B}(\mathrm{NF}-\kappa \mathrm{B})$ and heat shock factor-1 (HSF-1), electrophoretic mobility shift assays were performed.

Results: With the exception of indomethacin, the used immunosuppressive and anti-inflammatory agents sig-
\end{abstract}

nificantly inhibited $\mathrm{T}$ cell proliferation in response to influenza virus antigen in a dose-dependent manner. Interestingly, CyA and indomethacin did not suppress tumor necrosis factor- $\alpha$ (TNF- $\alpha$ )-induced adhesion molecule expression on HUVECs, whereas aspirin had an inhibitory effect. These observations correlated with the modulation of NF- $\kappa \mathrm{B}$ activity in EC. All agents tested induced expression of Hsp60 $6 \mathrm{hr}$ after application. In addition, aspirin and indomethacin, but not CyA, induced Hsp70 expression in HUVECs that correlated with induction of HSF-1 activity.

Conclusion: Our results show that the tested agents (except indomethacin) are inhibitors of the T cell-mediated immune response, as expected, that aspirin is an effective suppressor of adhesion molecule expression, and that all three agents can induce Hsp60 in HUVECs. These data provide the molecular basis for the notion that (1) part of the anti-atherogenic effect of aspirin may be due to the prevention of the adhesion of sensitized $T$ cells to stressed EC; (2) that part of the atherosclerosispromoting effect of CyA may be due to its potential as an inducer of Hsp60 expression and its inability to downregulate adhesion molecule expression on EC; and (3) that down-regulation of $\mathrm{MCP}-1$ expression by aspirin may result in decreased recruitment of monocytes into the arterial intima beneath stressed EC.

\section{Introduction}

Results in the past few years from different laboratories suggest an immunological contri-

Address correspondence and reprint requests to: Georg Wick, M.D., Institute for Biomedical Aging Research, Austrian Academy of Sciences, Rennweg 10, A-6020 Innsbruck, Austria. Phone: 43-512-58 39 19, or 43-512-507 3100; Fax: 43-512-58 39 198, or 43-512-507 2867; E-mail: iba@oeaw.ac.at bution to the development of atherosclerosis. It was shown that, in addition to macrophages, $T$ lymphocytes are also a fundamental component of early atherosclerotic lesions $(1,2)$, and these $\mathrm{T}$ lymphocytes are predominantly $\mathrm{CD} 4^{+}$ interleukin-2 (IL-2R) and HLA-DR receptor positive, indicating an activated phenotype $(3,4)$. Recently, it was shown that atheroscle- 
rotic lesions induced in mice or rabbits $(5,6)$ by a high cholesterol diet also exhibit infiltration and activation of $\mathrm{T}$ lymphocytes.

Based on observations in humans and experimental animals, we have advanced an immunological hypothesis for atherogenesis $(7,8)$, in which cellular and humoral immune reactions to heat shock protein 60 (Hsp60) have been identified as the initiating factors. This hypothesis is corroborated by the finding that immunization of normocholesterolemic rabbits with recombinant mycobacterial heat shock protein 65 (Hsp65) induces the development of arteriosclerotic lesions, and that the majority of $\mathrm{T}$ lymphocytes isolated from these lesions react against Hsp65 in vitro $(5,9)$. Furthermore, an epidemiological study showed that serum antibody titers to hsp65 were significantly increased in clinically healthy subjects with sonographically demonstrable carotid atherosclerosis compared to those without lesions (10). Hsp65 belongs to a family of proteins induced by various forms of stress, such as temperature, cytokines, toxins, and oxidized low-density lipoproteins. One of their important functions is protecting other cellular proteins from denaturation to maintain their cellular functions (11). Hsps are phylogenetically highly conserved; mycobacterial Hsp65 exhibits a $>50 \%$ protein sequence homology to human Hsp60 (12). Hsp antigens are also important in inducing protective immune responses but, in view of the high sequence homology to Hsp60, this protection may have to be "paid for" in humans by an autoimmune cross-reaction (13).

Previous studies suggested that recruitment of activated T lymphocytes into inflammation sites is mediated by several adhesion molecules, e.g., the intercellular adhesion molecule-1 (ICAM-1), vascular cell adhesion molecule-1 (VCAM-1), endothelial leukocyte adhesion molecule-1 (ELAM-1; E-selectin), and chemoattractant proteins, such as monocyte chemoattractant protein-1 (MCP-1), expressed by endothelial cells. This mechanism was also suggested for the recruitment of $\mathrm{T}$ lymphocytes into the arterial wall $(14,15)$. The induction of adhesion molecule expression in endothelial cells overlaying atherosclerotic lesions has been demonstrated (16-18), and data from our laboratory revealed that different stressors, such as hemodynamic turbulance, $\mathrm{H}_{2} \mathrm{O}_{2}$, tumor necrosis factor $\alpha$ (TNF- $\alpha)$, and $E$. coli lipopolysaccharide, induce co-expression of adhesion molecules and Hsp60 in endothelial cells in vivo and in vitro $(19,20)$, providing the prerequisites for recruitment of anti-Hsp60-reactive $\mathrm{T}$ cells into the arterial intima and subsequent initiation of an autoimmune response.
The role of immune reactions in atherogenesis was analyzed by manipulating the immune system in various animal models of atherosclerosis. Cyclosporin A (CyA)-mediated T lymphocyte immunosuppression of rabbits and mice fed a cholesterol-rich diet resulted in enhanced atherosclerosis $(21,22)$. In contrast, aspirin, another anti-inflammatory agent, lowered the incidence of myocardial infarction and stroke in men (23). These conflicting observations may result from different mechanisms of action of these immunosuppressive and anti-inflammatory agents on adhesion molecule and Hsp expression, respectively, in endothelial cells. Transcriptional induction of the corresponding genes by various stressors is mediated by transcription factors that bind to specific DNA elements in the promotor region of these genes. Transcription factors, such as nuclear factor $-\kappa \mathrm{B}(\mathrm{NF}-\kappa \mathrm{B})$ and heat shock factor- 1 (HSF-1), are pleiotropic regulators of many genes involved in immune and inflammatory responses, including adhesion molecules and Hsps (24). Most studies analyzing the effects of antiinflammatory agents focused on the modulation of NF- $\kappa$ B activity by aspirin in cytokine-stimulated endothelial cells $(25,26)$. However, little is known about the action of immunosuppressive agents on the activity of other transcription factors in endothelial cells and their potential to induce adhesion molecule and Hsp expression. To detail the potential role of immunosuppressive and anti-inflammatory agents in atherosclerosis, we analyzed the effects of CyA, aspirin, and indomethacin on the expression of ICAM- 1, VCAM-1, ELAM-1, and MCP-1, and of Hsp60 and Hsp70 by endothelial cells after cytokine activation in vitro. In parallel, the efficiency of this treatment was assessed by analyzing peripheral blood lymphocyte proliferation in response to specific antigen stimulation (influenza virions). We also analyzed the role of transcription factor activity in endothelial cells after treatment with these agents to demonstrate how the effects of the immunosuppressive agents are mediated in endothelial cells on a molecular level.

\section{Materials and Methods}

\section{Isolation and In Vitro Culture of Peripheral Blood Mononuclear Cells (PBMC)}

PBMC from fifteen 20 to 35-year-old donors, 11 female and 4 male, were purified from heparinized blood by Ficoll-Paque (Pharmacia, Uppsala, Sweden) density centrifugation and washed twice in RPMI 1640 from Gibco (Grand Island, $\mathrm{NY})$ at room temperature. The cells $\left(10^{5} /\right.$ well $)$ 
were placed into 96-well flat-bottom microtiter plates (Falcon, Becton Dickinson, Lincoln Park, NJ) containing RPMI-1640 medium, supplemented with antibiotics (penicillin $10,000 \mathrm{U} / \mathrm{ml}$, streptomycin $10 \mathrm{mg} / \mathrm{ml}$, Gibco) and $10 \%$ fetal calf serum (SEBAK, Stuben, Austria) as culture medium. Inactivated intact influenza virions of three strains [Singapore/6/86 (HlNl), A/Johannesburg/33/94 (H3N2), or B/Beijing/184/93; 1 $\mathrm{mg} / \mathrm{ml}$; Inflexal-Berna ${ }^{\circledR}$, kindly provided by the Schweizer Serum $\&$ Impfinstitut Bern, Switzerland] were added for stimulation. Nonspecific stimulation of PBMC by phytohemagglutinin (PHA) ( $1 \mu \mathrm{g} / \mathrm{ml}$, Sigma, St. Louis, MO) was performed as control. PBMC were then cultured in a $5 \% \mathrm{CO}_{2}$ atmosphere at $37^{\circ} \mathrm{C}$ for 7 days and finally pulsed with $1 \mu \mathrm{Ci}$ of ${ }^{3} \mathrm{H}$-thymidine (Amersham, Buckinghamshire, UK) for $8 \mathrm{hr}$. All assays were carried out in triplicate. Cells were harvested and proliferation rates determined as previously described (27). PBMC from each donor were cultured at $37^{\circ} \mathrm{C}, 5 \% \mathrm{CO}_{2}$ and analyzed for in vitro proliferation in response to stimulation with inactivated influenza virus.

\section{Endothelial Cell (EC) Preparation and Culture}

Human umbilical vein endothelial cells (HUVECs) were isolated from umbilical cords (obtained from the Department of Gynecology and Obstrestics, University of Innsbruck) by collagenase IV ( $1 \mathrm{mg} / \mathrm{ml}$ in RPMI 1640 medium; Sigma, Munich) digestion for 20 min at room temperature. HUVECs were harvested and cultivated in endothelial cell medium from PromoCell (Heidelberg, Germany) on gelatin precoated $(0.2 \%$ solution, type B, Sigma) culture flasks (Falcon, Becton Dickinson). Cells were identified as endothelial cells (EC) by immunofluorescence staining for factor VIII antigen production (antibody M0616 from Dakopatts, Glostrup, Denmark). The second to fifth passages of EC were used for all experiments.

\section{Application of Immunosuppressive Agents to EC}

EC were cultivated in culture flasks until they reached confluence. The cells were then washed with phosphate-buffered saline (PBS, $\mathrm{pH}$ 7.2) and cultivated in new EC medium supplemented with TNF- $\alpha$ (10 ng/ml; Sigma) and various concentrations of immunosuppressive agents, or with immunosuppressive agents alone for $6 \mathrm{hr}$. Thereafter, the medium was removed and cells were washed and collected for Northern blots and gel shift assays.
CyA from Sandimmune ${ }^{\circledR}$ (Sandoz, Switzerland) was dissolved in the solution supplied by the manufacturer and diluted to end concentrations in endothelial cell or RPMI medium. Aspirin (acetylsalicylic acid, Sigma) was dissolved in EC medium to give a $1 \mathrm{M}(180.2 \mathrm{mg} / \mathrm{ml})$ solution. The $\mathrm{pH}$ of the medium containing aspirin was adjusted prior to usage. Indomethacin (Sigma) was dissolved in dimethylsulfoxide (DMSO; Merck, Darmstadt, Germany) to prepare a 10 $\mathrm{mg} / \mathrm{ml}$ solution. This solution was then diluted in EC or RPMI medium to the final concentrations given in the Results section.

\section{RNA Isolation and Northern Blots}

Total RNA was isolated from EC according to a standard protocol (28). The RNA was electrophoresed in a $1 \%$ formaldehyde agarose gel, blotted on a nylon membrane (Zeta probe, BioRad, Richmond, VA) and UV cross-linked. The filters were hybridized with ${ }^{32} \mathrm{P}$-labeled cDNA $\left({ }^{32} \mathrm{P}-\alpha\right.$ dCTP, Amersham, London) and random primed using a labeling kit (Boehringer-Mannheim, Mannheim, Germany) for ICAM-1, VCAM-1, ELAM-1, Hsp60, Hsp70, $\beta$-actin, or GAPDH at $63^{\circ} \mathrm{C}$ in hybridization buffer (29). After three washing steps, filters were exposed to X-OMAT X-ray film from Kodak (Rochester, NY) at $-70^{\circ} \mathrm{C}$. The cDNA clones used in these experiments were the same as described earlier (20).

\section{Extraction of Nuclear Protein for NF- $\mathrm{\kappa B}$ and $\mathrm{HSF}-1$ Detection}

EC were washed in ice-cold PBS, harvested in 1 ml TE-buffer ( $10 \mathrm{mM}$ Tris $\mathrm{Cl}, 1 \mathrm{mM}$ EDTA, pH 8, Merck) and pelleted at $17,000 \times g$ for $5 \mathrm{~min}$. The pellet was resuspended in buffer A containing 10 mM Hepes (pH 7.9), $0.1 \mathrm{mM}$ EDTA, $10 \mathrm{mM} \mathrm{KCl}$, $0.1 \mathrm{mM}$ EGTA, $1 \mathrm{mM}$ DTT supplemented with $400 \mu \mathrm{M}$ phenylmethylsulfonyl fluoride (PMSF), $2 \mu \mathrm{M}$ leupeptin, $10 \mathrm{U} / \mathrm{ml}$ aprotinin, and $1 \mathrm{mM}$ pefablock SC [4-(2-aminoethyl)-benzenesulfonyl floride hydrochloride, Boehringer-Mannheim] and incubated on ice for $15 \mathrm{~min}$. After addition of $0.6 \%$ nonidet P-40 (Igepal CA-630, Sigma), the nuclei were pelleted at $17,000 \times g$ for $0.5 \mathrm{~min}$ and resuspended in buffer $\mathrm{B}$ containing $20 \mathrm{mM}$ Hepes, $0.4 \mathrm{M} \mathrm{NaCl}, 1 \mathrm{mM}$ EDTA, 1.5 $\mathrm{mM} \mathrm{MgCl}, 20 \%$ glycerol, $1 \mathrm{mM}$ EGTA and $1 \mathrm{mM}$ DTT supplemented with the same amount of protease inhibitors as buffer A. After incubation on ice for $15 \mathrm{~min}$ and continuous vortexing, the probes were centrifuged at $17,000 \times g$ for $5 \mathrm{~min}$. 
The supernatant was harvested and protein concentration measured with Bio-Rad protein assay reagent obtained from Bio-Rad Laboratories (Richmond, CA).

\section{Electrophoretic Mobility Shift Assays (EMSA)}

NF-KB. For gel mobility shift assays, $5 \mu \mathrm{g}$ of the nuclear protein extract was incubated with $1 \mathrm{ng}$ of an oligonucleotide containing the NF- $\kappa$ B binding sequence labeled with $\left(\gamma_{-}{ }^{32} \mathrm{P}\right)$ ATP (Amersham) and T4-polynucleotide kinase (Stratagene, La Jolla, CA). Reaction buffer contained $10 \mathrm{mM}$ Tris (pH 7.5), $1 \mathrm{mM}$ EDTA, $50 \mathrm{mM} \mathrm{NaCl}$, $5 \%$ glycerol, $1 \mathrm{mM}$ DTT, and $1 \mu \mathrm{g}$ poly(dIdC) (Pharmacia) as a nonspecific inhibitor. Samples were electrophoresed through a $4 \%$ polyacrylamide gel and exposed to autoradiographic film (X-OMAT, Kodak).

HSF-1. For gel mobility shift assays, $5 \mu \mathrm{g}$ of the nuclear protein extract was incubated with $1 \mathrm{ng}$ of an oligonucleotide containing the HSF binding sequence (HSE) labeled with $\left(\alpha-{ }^{32} \mathrm{P}\right) \mathrm{dCTP}$ (Amersham) and the Random Primed DNA Labeling Kit (Boehringer-Mannheim). Reaction buffer contained $10 \mathrm{mM}$ Hepes (pH 7.9), 1 mM DTT, l $\mathrm{mM}$ EDTA, $4 \%$ Ficoll, $80 \mathrm{mM} \mathrm{KCl}$, and $1 \mu \mathrm{g}$ poly(dIdC) as a nonspecific inhibitor. Electrophoresis and detection was performed as described for NF- $\kappa$ B.

\section{Results}

Suppression of PBMC Proliferation by Immunosuppressive Agents In Vitro

To functionally assess immunosuppression by anti-inflammatory treatment, we investigated immunosuppressive agents on PBMC proliferation after stimulation with influenza virions in vitro. Various doses of immunosuppressive agents were administered to PBMC co-cultivated with influenza virion mix and cell proliferation was measured after 7 days. Figure 1 shows that aspirin and CyA inhibited PBMC proliferation in a dose-dependent fashion, whereas indomethacin had no suppressive effect (Fig. 1C). Aspirin at concentrations between $5 \mathrm{mM}(0.9 \mathrm{mg} / \mathrm{ml})$ and $40 \mathrm{mM}(7.2$ $\mathrm{mg} / \mathrm{ml}$ ) and CyA at concentrations of 100 $\mathrm{ng} / \mathrm{ml}$ and more inhibited $\mathrm{PBMC}$ proliferation (Fig. 1) in a dose-dependent manner. To examine interindividual differences in the PBMC
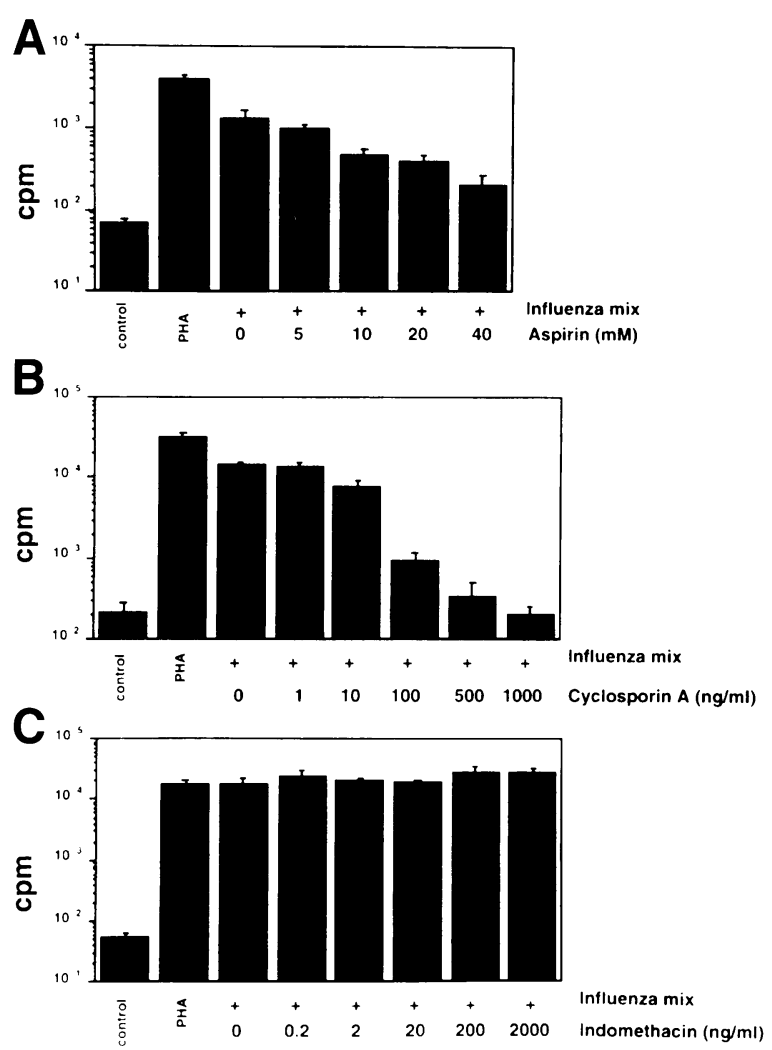

Fig. 1. Effects of immmunosuppressive/antiinflammatory agents on PBMC proliferation. PBMC were Co-cultivated with inactivated intact influenza virions and various agents, including aspirin $(\mathrm{A})$, CyA (B), and indomethacin $(\mathrm{C})$, used in the indicated concentrations to detect their effectiveness. Proliferation assays were performed after 7 days. As a control, unspecific stimulation of PBMC by PHA ( $1 \mu \mathrm{g} / \mathrm{ml}$ ) was used. The figure shows a representative example of 1 of 15 patients examined $(n=15$, $p<0.05, \mathrm{SD})$.

response to immunosuppressive agents, 15 donors, aged $20-35$ years, were analyzed. While the specific response of PBMC proliferation to influenza virus mix stimulation differed among donors (not shown), suppression of cell proliferation by CyA and aspirin was comparable. Cell viability was measured in parallel cultures on day 7 by propidium iodide (PI) staining and FACS analysis. No increased cell death was observed in PBMC cultured in medium supplemented with immunosuppressive agents versus PBMC cultivated in normal culture medium (not shown).

Modulation of EC Activation by Immunosuppressive Agents

HUVEC monolayers were cultivated in EC medium supplemented with TNF- $\alpha$ and various 
A

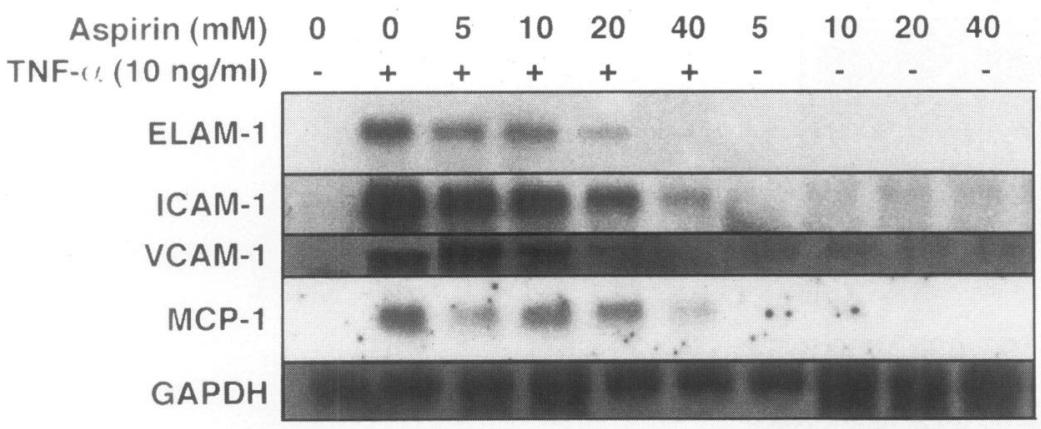

B

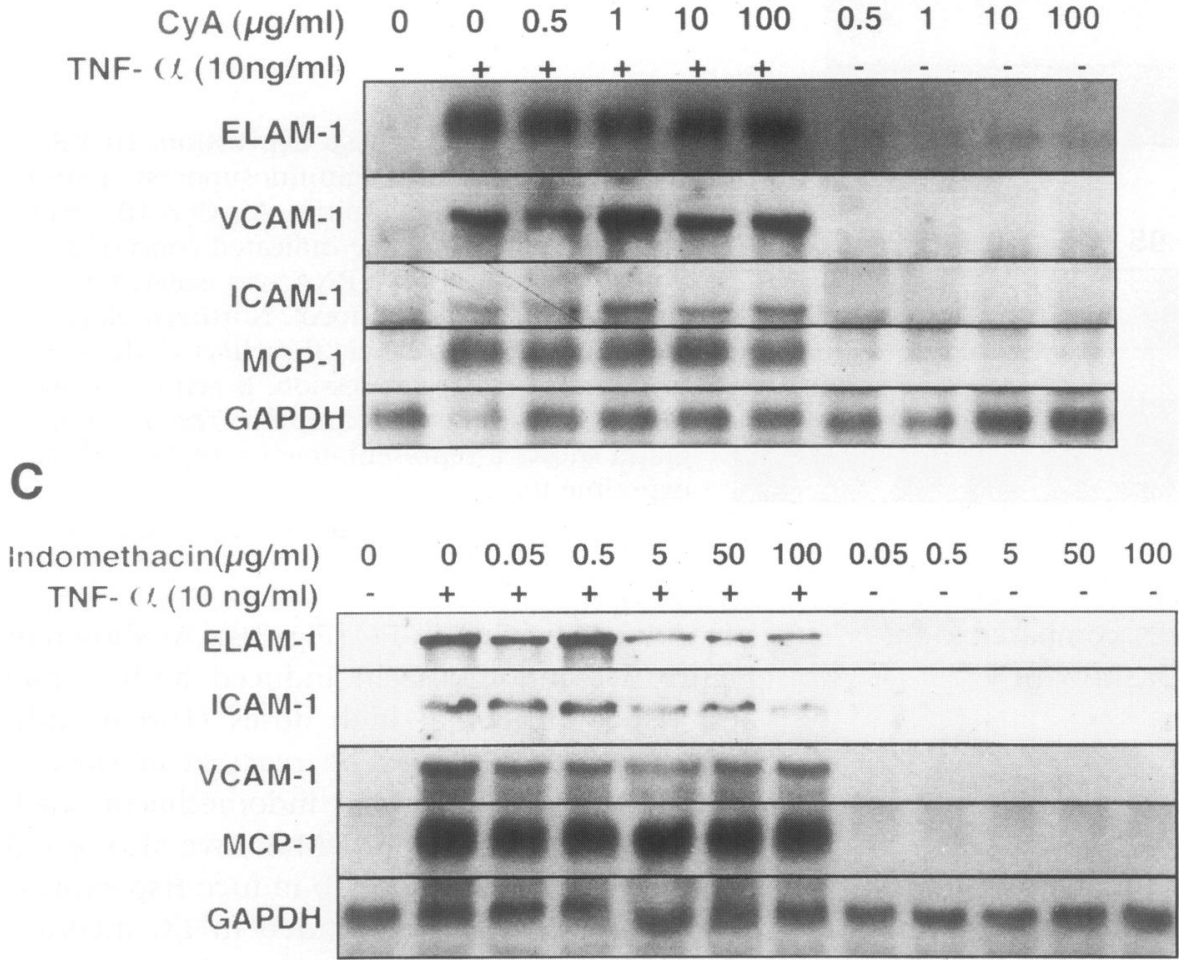

Fig. 2. Effects of various agents on expression of adhesion molecules. HUVECs were cultivated in fresh medium containing the indicated concentrations of aspirin (A), CyA (B), and indomethacin $(C)$ in the presence or absence of TNF- $\alpha$ (10 ng/ml) for $6 \mathrm{hr}$. Northern blots were performed with total RNA. Only aspirin shows an inhibitory effect on the expression of adhesion molecules. GAPDH was used to standardize the RNA amount. The autoradiograph is a representative example of three experiments.

concentrations of immunosuppressive, anti-inflammatory agents, or in medium supplemented with immunosuppressive agents alone. Figure 2 demonstrates that TNF- $\alpha$ induced expression of adhesion molecules ICAM-1, VCAM-1, ELAM-1, and the chemoattractant protein MCP-1. This induction was constantly suppressed by concentrations of aspirin between 5 and $40 \mathrm{mM}(0.9 \mathrm{mg} / \mathrm{ml}-7.2 \mathrm{mg} / \mathrm{ml})$ (Fig. 2A). In contrast, CyA and indomethacin did not suppress induction of adhesion molecules and MCP-1 by TNF- $\alpha$ (Fig. 2B, C). None of the immunosuppressive agents alone induced adhesion molecules or MCP-1 in EC. Since local conditions in vivo could favor up- take of immunosuppressive agents and concentrate them at distinct sites, we also tested high concentrations of indomethacin and CyA. As shown in Figure 2 B, C, concentrations as high as $100 \mathrm{mg} / \mathrm{ml}$ of CyA or indomethacin (except at the highest concentration) failed to suppress induction of adhesion molecules and MCP-1 expression by TNF- $\alpha$, and were not effective in inducing adhesion molecules or MCP-1. EC viability during experiments with anti-inflammatory agents was analyzed by determination of apoptosis by PI staining of nuclei followed by flow cytometry (30). Apoptosis was not significantly increased in EC cultivated in medium supplemented for $6 \mathrm{hr}$ with anti-inflam- 


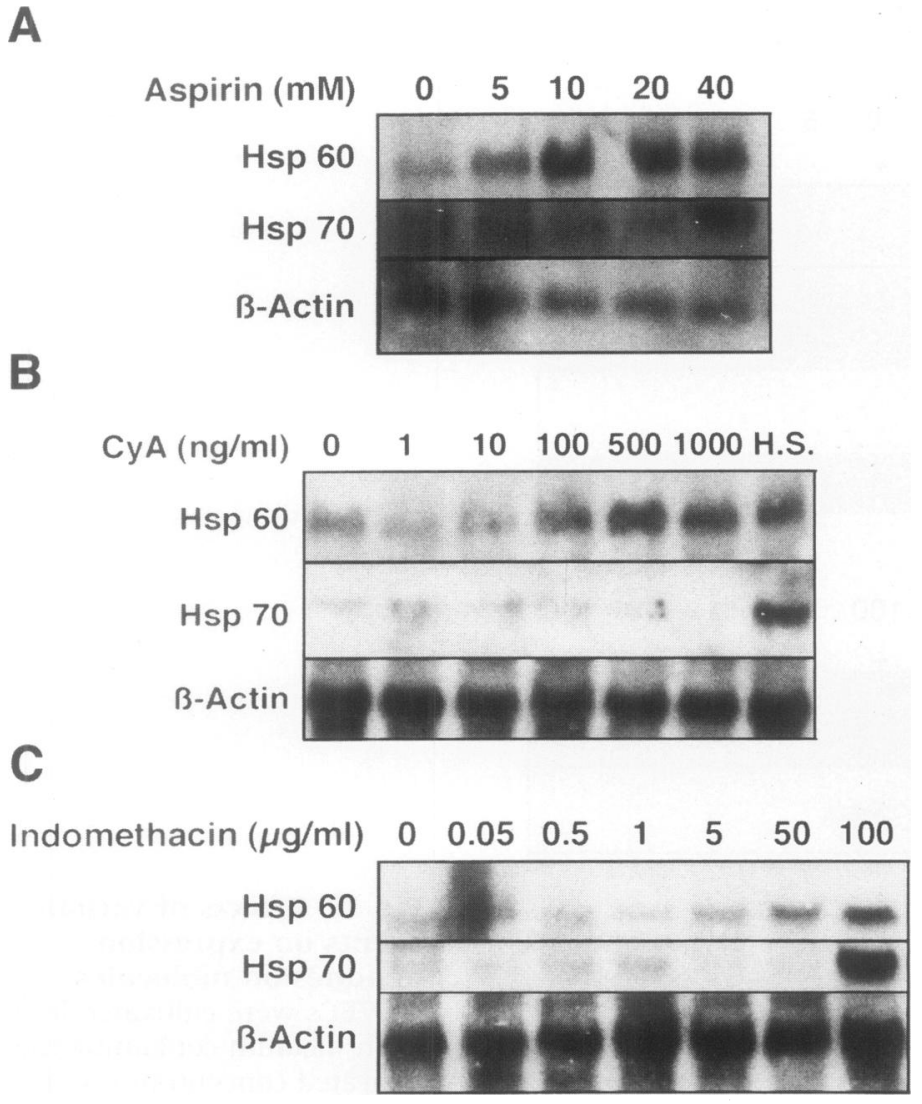

Fig. 3. Induction of Hsp expression. HUVECs were treated with the immunosuppressive/antiinflammatory agents aspirin (A), CyA (B), and indomethacin $(\mathrm{C})$ at the indicated concentrations for $6 \mathrm{hr}$ and total RNA was isolated according to standard protocol. Northern blots were performed to detect the effect of the various agents on Hsp expression. $\beta$-actin was used to standardize the RNA amount. The autoradiograph shows a representative example of three experiments. matory agents, even at high doses, compared to EC cultivated in medium alone (not shown).

Induction of Heat Shock Proteins in HUVECs by Aspirin, CyA, and Indomethacin

The same preparations of HUVECs were used in parallel studies to examine the ability of immunosuppressive agents to induce Hsp60 and Hsp70 expression. Results of a first series of experiments confirmed earlier studies from our laboratory: TNF- $\alpha$ alone is a potent inducer of Hsp60 expression in endothelial cells (20). We then examined the effect of immunosuppressive agents on EC without addition of TNF- $\alpha$ to the culture medium. Figure 3 shows that Hsp60 mRNA was slightly expressed in EC under normal-certainly also somewhat stressful-culture conditions. Aspirin concentrations of 5 to $40 \mathrm{mM}$ induced expression of Hsp60 mRNA compared to untreated control cells. Furthermore, aspirin induced expression of Hsp70 mRNA only at high concentrations (Fig. 3A). CyA in concentrations from $100 \mathrm{ng} / \mathrm{ml}$ to $1000 \mathrm{ng} / \mathrm{ml}$ induced the expression of Hsp60 mRNA compared to untreated control cells. In contrast, Hsp70 expression was not induced by CyA in EC (Fig. 3B). As shown in Figure 3C, indomethacin induced both Hsp60 and Hsp70 mRNA at high doses $(100 \mu \mathrm{g} / \mathrm{ml})$. This concentration may be reached at sites of favored uptake. Since the indomethacin stock solution was dissolved in DMSO, we also tested the ability of DMSO alone to induce Hsp expression in EC. DMSO was diluted in EC medium and applied to EC for $6 \mathrm{hr}$. Hsp 60 and Hsp 70 mRNA trancription was not significantly induced by DMSO alone in the same concentration as that needed for application of $100 \mu \mathrm{g} / \mathrm{ml}$ indomethacin (data not shown).

\section{Effects of Immunosuppressive Agents on Transcription Factor Activation}

The modulation of HSF- 1 and NF- $\kappa$ B activity by immunosuppressive agents was assessed in different preparations of HUVECs. Nuclear protein extracts from EC treated with immunosuppressive agent were isolated and incubated with labeled oligonuclotides containing the DNA-binding sequences for NF- $\kappa$ B and HSF-1, respectively. As shown in Figure 4B, CyA, aspirin, and indomethacin themselves did not induce NF- $\kappa$ B ac- 


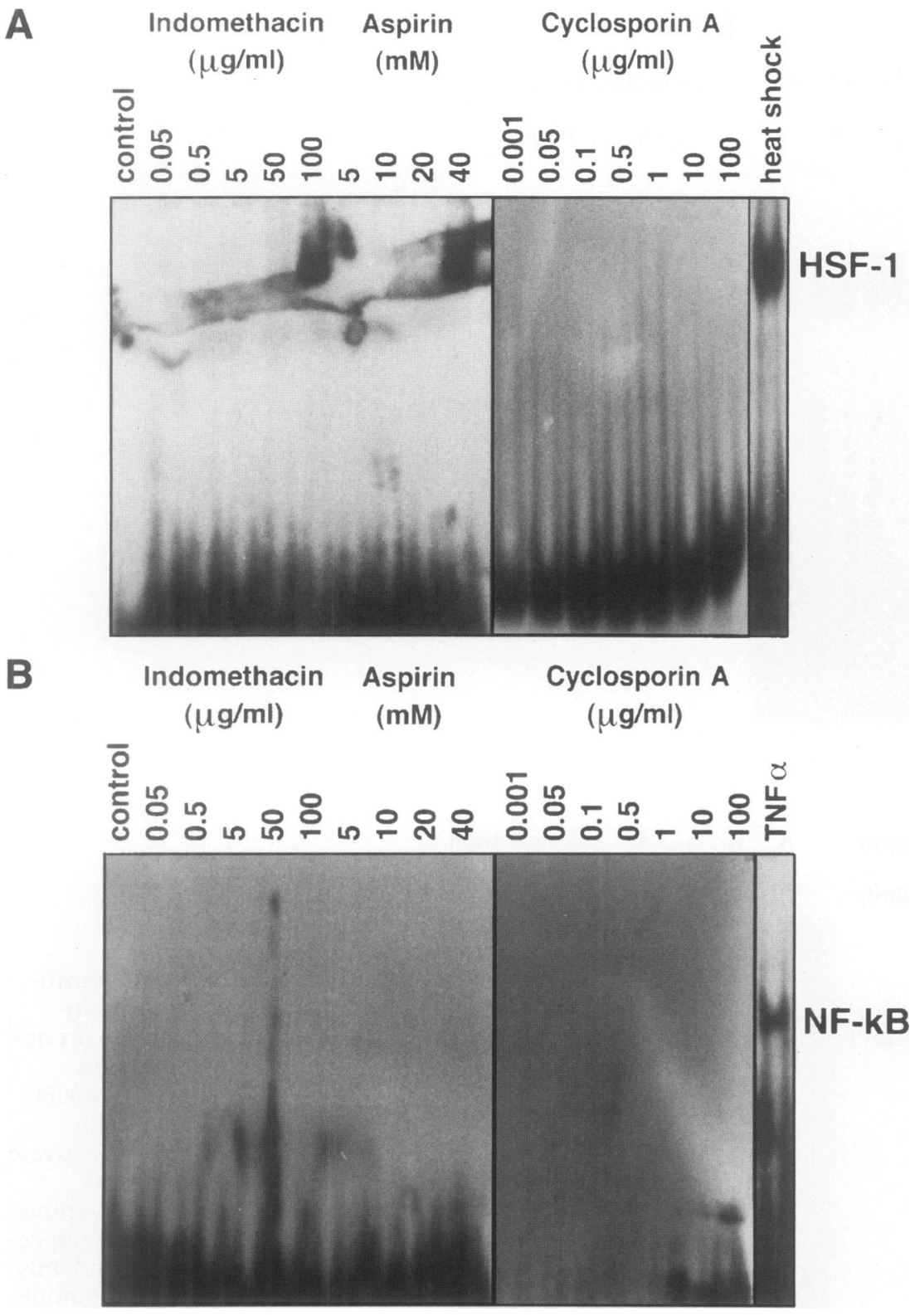

Fig. 4. Effects of immunosuppressive/anti-inflammatory agents on transcription factor activation. HUVECs were treated with various immunosuppressive agents at the indicated concentrations and nucleic protein was extracted according to the protocol. For the EMSA, $5 \mu \mathrm{g}$ of the nucleic protein was incubated with $1 \mathrm{ng}$ of a radioactively labeled oligonucleotide containing the NF- $\kappa \mathrm{B}$ binding sequence $(B)$ or the HSF binding sequence $(A)$. tivity in EC. However, high concentrations of aspirin $(40 \mathrm{mM} ; 7.2 \mathrm{mg} / \mathrm{ml})$, indomethacin $(40$ $\mathrm{mg} / \mathrm{ml})$, and heat shock $\left(42^{\circ} \mathrm{C}\right.$ for $\left.30 \mathrm{~min}\right)$, but not CyA, induced HSF-1 binding of EC nuclear protein extracts (Fig. 4A). TNF- $\alpha$-induced NF- $\kappa$ B activity in EC is suppressed by aspirin (Fig. 5A), but not by indomethacin (Fig. 5B) or CyA (Fig. 5C). The inhibition of NF- $\kappa \mathrm{B}$ activity was observed by treatment with concentrations of aspirin ranging from 10 to $40 \mathrm{mM}(1.8 \mathrm{mg} / \mathrm{ml}-$ $7.2 \mathrm{mg} / \mathrm{ml}$ ) (Fig. 5A). The specificity of the shown NF- $\kappa \mathrm{B}$ binding was confirmed by competition with a 50 -fold excess of cold NF- $\kappa$ B, a supershift using an anti-NF- $\kappa \mathrm{B}$ antibody, and by using a 50-fold excess of cold HSE (Fig. 6).

\section{Discussion}

In this study, we have demonstrated that the action of immunosuppressive and anti-inflammatory agents such as CyA, aspirin, and indomethacin, differs with respect to suppression of specific lymphocyte responses to antigen and their effect on ICAM-1, VCAM-1, ELAM-1, and MCP-1 expression on activated endothelial cells in vitro. Importantly, we have also shown that CyA and aspirin can induce Hsps.

CyA blocks early events in antigen recognition and activation of $\mathrm{T}$ cells by binding to cyclophilin and subsequent prevention of the expression of IL-2. However, CyA is less effective in 
A
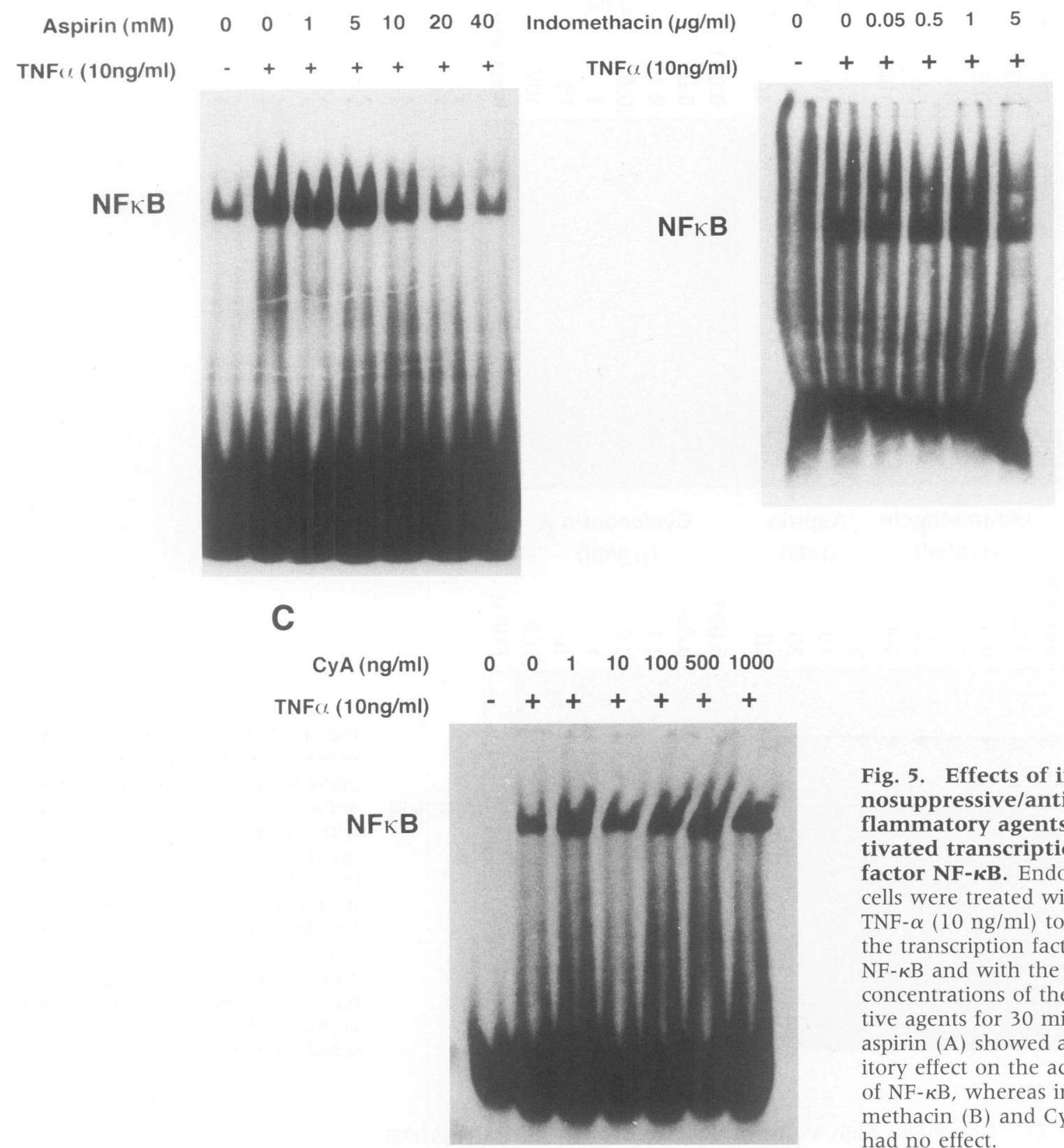

Fig. 5. Effects of immunosuppressive/anti-inflammatory agents on activated transcription factor NF- $\mathbf{B B}$. Endothelial cells were treated with TNF- $\alpha(10 \mathrm{ng} / \mathrm{ml})$ to activate the transcription factor $\mathrm{NF}-\kappa \mathrm{B}$ and with the various concentrations of the respective agents for $30 \mathrm{~min}$. Only aspirin (A) showed an inhibitory effect on the activation of NF- $\kappa \mathrm{B}$, whereas indomethacin (B) and CyA (C) had no effect. blocking responses of activated $\mathrm{T}$ cells to presentation of antigen (31). Since CyA is an effective suppressor of $\mathrm{T}$ cell activation, it was used as a possible tool to examine the role of $\mathrm{T}$ cells in atherogenesis. Surprisingly, it was shown that CyA administration was associated with an increased severity of atherosclerosis in cholesterolfed rabbits (21) and mice given an atherogenic diet (22). Although administration of CyA resulted in suppression of cell-mediated immunity, no gross changes in the number of lymphocytes within atherosclerotic lesions was observed in these rabbits. Emeson and Shen suggested that this result was due to increased low-density lipoprotein (LDL) cholesterol by CyA (22). Studies by Roselaar et al. (21) gave similar results in CyA-treated rabbits, but they did not observe any changes in LDL metabolism. These authors discussed the possibility that atherosclerosis in these mice developed through changes in specific cytokine-mediated effects (21). Based on previous observations from our laboratory, we hy- 


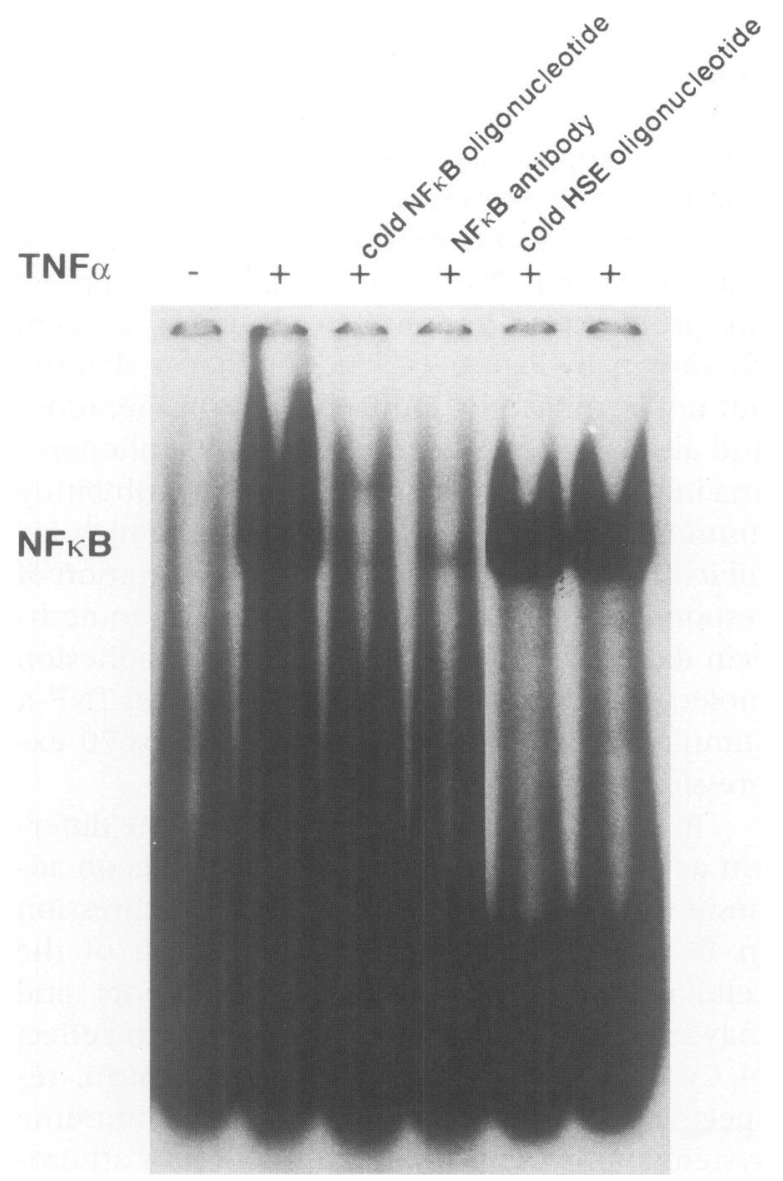

Fig. 6. Specifity of NF- $\mathrm{BB}-$ binding activity in endothelial cells in response to TNF- $\alpha$. Nuclear proteins of endothelial cells treated with TNF- $\alpha$ (10 $\mathrm{ng} / \mathrm{ml}$ ) for $30 \mathrm{~min}$ were incubated with ${ }^{32} \mathrm{P}$-labeled $\mathrm{NF}-\kappa \mathrm{B}$ oligonucleotide in the presence or absence of unlabeled oligonucleotide containing NF- $\kappa \mathrm{B}$ or HSE binding element (cold oligonucleotide). Incubation with an NF- $\kappa$ B antibody led to a supershifted DNAbinding complex.

pothesize that recruitment of Hsp65/60-reactive $\mathrm{T}$ cells into the intima is a crucial step in the initiation of atherosclerosis, and that sensitization of these $\mathrm{T}$ cells probably occurs at more distant sites, such as draining lymph nodes $(6,7)$. Adhesion molecule and MCP-1 expression by endothelial cells are necessary for recruitment of activated $\mathrm{T}$ cells into the arterial intima because of the relatively low binding affinity of the $\mathrm{T}$ cell receptor to its antigen. For the initiation of the immune response in atherosclerosis a fine balance between the adhesion molecule and the Hsp60 surface expression seems to be required. Hsp60-reactive T cells could show prolonged adherence to stressed, adhesion molecule-expressing endothelial cells, recognizing Hsp60 and thus evoking endothelial injury via cell-mediated cytotoxicity.

As shown in this study, CyA is not effective in suppressing adhesion molecule and MCP-1 expression after induction by TNF- $\alpha$. This lack of suppression of adhesion molecule and MCP-1 expression by CyA may be partially explained by the inability to inactivate the transcription factor NF- $\kappa$ B in EC. Cockerill et al. demonstrated that CyA can inhibit granulocyte-macrophage colony-stimulating factor and ELAM-1 expression in endothelial cells (32). This controversial observation could be due to the fact that in their study they added CyA 10 min before stimulation of adhesion molecule expression by TNF- $\alpha$ and interferon $\gamma($ IFN- $\gamma)$. Furthermore, the inhibition of ELAM-1 expression was $40 \%$ compared to that of the control, which may not be sufficient to inhibit the recruitment of activated $\mathrm{T}$ cells. More importantly, CyA emerged as an inducer of Hsp60 in human EC at concentrations sufficient to suppress antigen-specific $T$ cell proliferation in vitro (Figs. 1 and $3 \mathrm{~B}$ ) and $\mathrm{T}$ cell immunity to allogenic skin grafts in vivo (21). We suggest, therefore, that the enhancement of atherosclerosis in cholesterol-fed rabbits and mice $(21,22)$ is due to induction of Hsp60 by EC. Since the immunosuppressive effect of CyA is most prominent during the induction phase of a $\mathrm{T}$ cell response, and less so in Hsp60-reactive memory cells, the Hsp60 and adhesion molecule-inducing effect obviously overrides the former, although the mechanism of induction is not known. The promotor region of the human Hsp60 gene remains to be cloned and analyzed. Thus, it is difficult to define the transcription factor(s) responsible for CyA-induced Hsp60 expression. We found that CyA did not induce HSF-1 in EC, as was shown to be necessary for Hsp70 gene expression in many different cell types (33).

More recently, Drew and Tipping demonstrated that CyA treatment reduces atherosclerosis in cholesterol-fed rabbits (34). The authors showed that no $\mathrm{CD} 4^{+}$cells could be detected in the few plaques of CyA-treated animals, whereas circulating $\mathrm{T}$ cell numbers and subsets were unaffected. In this study, rabbits were analyzed 4 weeks after starting the cholesterol-rich diet compared to studies by others in which lesions developed over periods of $4-8$ months (21). It is tempting to suggest that, in CyA-treated animals, lesion formation might be delayed, but not inhibited.

Aspirin and indomethacin belong to a class of nonsteroidal anti-inflammatory drugs, and as- 
pirin is commonly used to treat certain symptoms of inflammatory and cardiovascular diseases. Recently, it was shown that aspirin treatment of clinically apparently healthy men with high base-line C-reactive protein serum levels was associated with a decreased risk for a first myocardial infarction, suggesting that the antiinflammatory effect of aspirin may have clinical benefits in preventing cardiovascular disease (23). However, in contrast to its use in preventing atherosclerosis, higher doses of aspirin are necessary to treat inflammatory diseases (35). Recent studies have shown that high doses of aspirin inhibit the activation of NF- $\kappa$ B (Fig. 5A) by preventing inhibitor-kB degradation, which is necessary for release and nuclear translocation of NF- $\kappa \mathrm{B}$ from the inactive cytoplasmic complex $(25,26,36)$. Suppression of NF- $\kappa \mathrm{B}$ activation correlates with decreased adhesion molecule and MCP-1 expression by anti-inflammatory agents (Fig. 3). High doses of aspirin (from 10 to $40 \mathrm{mM}$; $1.8 \mathrm{mg} / \mathrm{ml}$ to $7.2 \mathrm{mg} / \mathrm{ml}$ ) may be observed in vivo because the local conditions may favor its uptake and concentration, possibly enhancing inhibition of NF- $\kappa B$ at these sites (37). In the current study, we demonstrated that doses of aspirin that effectively suppress adhesion molecule and MCP-1 expression also effectively induce Hsp60 and Hsp70. Hsp70 expression induced by aspirin correlates with HSF- 1 activity in endothelial cells, suggesting that HSF-1 is involved in aspirin-induced Hsp70 expression. Jurivich et al. (38) have shown that sodium salicylate at concentrations as high as $20 \mathrm{mM}(3.6$ $\mathrm{mg} / \mathrm{ml}$ ) induces HSF binding to HSE of the Hsp70 gene, even though it was unable to induce Hsp70 transcription in HeLa cells. We found HSF-1 binding to HSE and transcription of Hsp70 gene only at aspirin concentrations of $40 \mathrm{mM} 7.2 \mathrm{mg} /$ $\mathrm{ml}$. The expression of Hsp60 is induced at concentrations of aspirin ranging from 10 to $40 \mathrm{mM}$.

Our data suggest that high doses of aspirin prevent the recruitment of activated $\mathrm{T}$ cells (even of known specificity) into sites of inflammation via suppression of adhesion molecules and MCP-1, in concert with the finding that aspirin inhibits NF- $\kappa \mathrm{B}$ activation (Fig. 5A). Neither indomethacin nor CyA showed this inhibitory effect (Fig. 5B, C). Furthermore, aspirin inhibited the proliferative response of PBMC to influenza virus mix in vitro, a suppression that was effective at aspirin concentrations that induced Hsp60 expression. Therefore, we hypothesize that the recruitment of anti-Hsp60-reactive $\mathrm{T}$ cells into arterial intima and the subsequent initiation of a reaction against Hsp60 could be prevented by aspirin. Furthermore, we assume that the induction of Hsp60 expression by aspirin cannot overcome the suppressive effects of aspirin on adhesion molecule expression.

We have also demonstrated that addition of indomethacin to $\mathrm{T}$ cell cultures failed to suppress the proliferative response to influenza antigen. As shown in Figure 1C, indomethacin slightly, but not significantly, induced $\mathrm{T}$ cell proliferation, and also reversed immune suppressive phenomena in vivo (39) and in vitro $(40,41)$ by inhibiting immune cell release of prostaglandin, which inhibits IL-2 production and hence proliferation of responder $\mathrm{T}$ cells (41). Furthermore, indomethacin did not inhibit NF- $\kappa$ B activity and adhesion molecule or MCP- 1 expression in EC after TNF- $\alpha$ stimulation, and induced Hsp60 and Hsp70 expression only at high doses.

In summary, our data suggest that the different actions of immunosuppressive agents on adhesion molecule, MCP-1, and Hsp60 expression in EC could overcome the suppression of the cellular immune response by these agents, and may explain the atherosclerosis-promoting effect of CyA and the protective effect of aspirin, respectively. Further investigations on immune system suppression in animal models of atherosclerosis will elucidate how and when lymphocytes influence the atherosclerotic disease process.

\section{Acknowledgements}

This work was supported by the Austrian Research Council Project 12715 (G. W.) and the Sandoz Foundation for Gerontological Research (G. W.) The authors thank G. Sturm for her excellent technical assistance and T. Öttl for his help in preparation of the photographs.

\section{References}

1. Hansson GK, Jonasson L, Lojsthed B, Stemme S, Kocher O, and Gabbiani G. (1988) Localization of $\mathrm{T}$ lymphocytes and macrophages in fibrous and complicated human atherosclerotic plaques. Atherosclerosis 72: 135-141.

2. Xu Q, Oberhuber G, Gruschwitz M, and Wick G. (1990) Immunology of atherosclerosis: cellular composition and major histocompatibility complex class II antigen expression in aortic intima, fatty streaks, and atherosclerotic plaques in young and aged human specimens. Clin. Immunol. Immunopathol. 56: 344-359. 
3. Hansson GK, Holm J, and Jonasson L. (1989) Detection of activated $\mathrm{T}$ lymphocytes in the human atherosclerotic plaque. Am. J. Pathol. 135: 169-175.

4. Stemme S, Holm J, and Hansson GK. (1992) Tlymphocytes in human atherosclerotic plaques are memory cells expressing CD45RO and the integrin VLA-1. Arterioscler. Thromb. 12: 206-211.

5. Xu Q, Kleindienst R, Waitz W, Dietrich H, Wick G. (1993) Increased expression of heat shock protein 65 coincides with a population of infiltrating $T$ lymphocytes in atherosclerotic lesions of rabbits specifically responding to heat shock protein 65 . J. Clin. Invest. 91: 2693-2702.

6. Zhou X, Stemme S, Hansson GK. (1996) Evidence for a local immune response in atherosclerosis: CD4+ T-cells infiltrate lesions of APO E-deficient mice. Am. J. Pathol. 149: 359-366.

7. Wick G, Kleindienst R, Dietrich H, Xu Q. (1992) Is atherosclerosis an autoimmune disease? Trends Food Sci. Technol. 3: 114-119.

8. Wick G, Schett G, Amberger A, Kleindienst R, Xu Q. (1995) Is atherosclerosis an immunologically mediated disease? Immunol. Today 16: 27-33.

9. Xu Q, Dietrich H, Steiner HJ, et al. (1992) Induction of arteriosclerosis in normocholesterolemic rabbits by immunization with heat shock protein 65. Arterioscler. Thromb. 12: 789-799.

10. Xu Q, Willeit J, Marosi M, et al. (1993) Association of serum antibodies to heat shock protein 65 with carotid atherosclerosis. Lancet 341: 255-259.

11. Ellis RJ, van der Vies SM. (1991) Molecular chaperones. Annu. Rev. Biochem. 60: 321-347.

12. Lamb JR, Bal V, Mendez-Samperio P, et al. (1989) Stress proteins may provide a link between the immune response to infection and autoimmunity. Int. Immunol. 1: 2-6.

13. Welch WJ. (1992) Mammalian stress response: cell physiology, structure/function of stress proteins and implications for medicine and disease. Physiol. Rev. 72: 1063-1081.

14. Ross R. (1993) The pathogenesis of atherosclerosis: a perspective for the 1990. Nature 362: 801809.

15. Springer TA. (1994) Traffic signals for lymphocyte recirculation and leukocyte emigration: the multistep paradigm. Cell 76: 301-314.

16. Van der Wal AC, Das PK, Tigges AJ, Becker AE. (1992) Adhesion molecules on the endothelium and mononuclear cells in human atherosclerotic lesions. Am. J. Pathol. 141: 1427-1433.

17. Printseva OY, Peclo MM, Gown AM. (1992) Various cell types in human atherosclerotic lesions express ICAM-1. Further immunocytochemical and immunochemical studies employing monoclonal antibody 10F3. Am. J. Pathol. 140: 889896.

18. Li H, Cybulsky MI, Gimbrone MA Jr, Libby P. (1993) Inducible expression of vascular cell adhesion molecule-1 by vascular smooth muscle cells in vitro and within rabbit atheroma. Am. J. Pathol. 143: 1551-1559.

19. Seitz SC, Kleindienst R, Xu Q, Wick G. (1996) Co-expression of heat shock protein 60 and intercellular adhesion molecule- 1 is related to increased adhesion of monocytes and T-cells to aortic endothelium of rats in response to endotoxin. Lab. Invest. 74: 241-252.

20. Amberger A, Maczeck C, Jürgens G, et al. (1997) Co-expression of ICAM-1, VCAM-1, ELAM-1 and Hsp60 in human arterial and venous endothelial cells in response to cytokines and oxidized low density lipoproteins. Cell Stress Chaperones 2: 94103.

21. Roselaar SE, Schonfeld G, Daugherty A. (1995) Enhanced development of atherosclerosis in cholesterol-fed rabbits by suppression of cell-mediated immunity. J. Clin. Invest. 96: 1389-1394.

22. Emeson EE, Shen M-L. (1993) Accelerated atherosclerosis in hyperlipidemic C57BL/6 mice treated with cyclosporin A. Am. J. Pathol. 142: 1906-1915.

23. Ridker PM, Cushman M, Stampfer MJ, Tracy RP, Hennekens CH. (1997) Inflammation, aspirin and the risk of cardiovascular disease in apparently healthy men. N. Engl. J. Med. 336: 973-979.

24. Collins T, Read MA, Neish AS, Whitley MZ, Thanos D, Maniatis T. (1995) Trancriptional regulation of endothelial cell adhesion molecules: NF- $\kappa$ B and cytokine-inducible enhancers. FASEB J. 9: 899-909.

25. Kopp E, Ghosh S. (1994) Inhibition of NF- $\kappa$ B by sodium salicylate and aspirin. Science 265: 956959.

26. Weber C, Erl W, Pietsch A, Weber P. (1995) Aspirin inhibits nuclear factor- $\kappa \mathrm{B}$ mobilization and monocyte adhesion in stimulated human endothelial cells. Circulation. 91: 1914-1917.

27. Grubeck-Loebenstein B, Londei M, Greenal C, et al. (1988) Pathogenic relevance of HLA class II expressing thyroid follicular cells in nontoxic goiter and Graves disease. J. Clin. Invest. 81: 16081614.

28. Chomczynski P, Sacchi N. (1987). Single-step method of RNA isolation by acid guanidinium thiocyanate-phenol-chloroform extraction. Anal. Biochem. 162: 156-159.

29. Church GM, Gilbert W. (1984) Genomic sequencing. Proc. Natl. Acad. Sci. U.S.A. 81: 1991-1995.

30. Nicoletti I, Migliorati G, Pagliacci MC, Grignani F, Riccardi C. (1991) A rapid and simple method for measuring thymocyte apoptosis by propidium iodide staining and flow cytometry. J. Immunol. Methods 13: 271-279.

31. Schreiber SL, Crabtree GR. (1992) The mechanism of action of cyclosporin A and FK506. Immunol. Today. 13: 136-142.

32. Cockerill GW, Bert AG, Ryan GR, Gamble JR, Vadas MA, Cockerill PN. (1995) Regulation of granulocyte-macrophage colony-stimulating fac- 
tor and E-selectin expression in endothelial cells by cyclosporin $\mathrm{A}$ and the T-cell transcription factor NFAT. Blood 86: 2689-2698.

33. Zimarino V, Tsai C, Wu C. (1989) Complex modes of heat shock factor activation. Mol. Cell. Biol. 10: 752-759.

34. Drew AF, and Tipping PG. (1995) Cyclosporine treatment reduces early atherosclerosis in the cholesterol-fed rabbit. Atherosclerosis 116: 181-189.

35. Weismann G. (1991). Aspirin. Sci. Am. 264: 8492.

36. Pierce JW, Read MA, Ding H, Luscinskas FW, Collins, T. (1996) Salicylate inhibit I $\kappa \mathrm{B}-\alpha$ phosphorylation, endothelial-leukocyte adhesion molecule expression, and neutrophil transmigration. J. Immunol. 156: 3961-3969.

37. Palmoski MJ, Brandt KD. (1984) Effects of salicylate and indomethacin on glycosaminoglycan and prostaglandin E2 synthesis in intact canine knee cartilage ex vivo. Arthritis Rheum. 27: 398-404.

38. Jurivich DA, Sistonen L, Kroes RA, Morimoto RI. (1992) Effect of sodium salicylate on the human heat shock response. Science 25: 1243-1245.

39. Hernandez-Pando R, Orozco H, Mancilla R. (1995) T-cell lung granulomas induced by sepharose-coupled mycobacterium tuberculosis protien antigens: immunosuppressive phenomena reversed with cyclophosphamide and indomethacin. Immunology 8: 506-511.

40. Stefanovic H, Filion LG. (1990) Effect of IL-2 and indomethacin on the activation of suppressor cells induced by tetanus toxoid. Immunobiology 18: 345-356.

41. Marcinkiewicz J, Grabowska A, Chain BM. (1996). Is there a role for nitric oxide in regulation of $\mathrm{T}$ cell secretion of Il-2? J. Immunol. 15: 4617-4621. 